\title{
THE CONFOCAL SCANNING LASER MICROSCOPIC STUDY OF THE PITTING CORROSION ON SPUTTER-DEPOSITED W-Ti ALLOYS IN 1 M NaOH SOLUTION
}

\author{
Jagadeesh Bhattarai*
}

\begin{abstract}
The pitting corrosion of the passive films formed on the surface of sputter-deposited W-30Ti and W-53Ti alloys after immersion for 24 hours in alkaline $1 \mathrm{M} \mathrm{NaOH}$ soution at $25^{\circ} \mathrm{C}$ was studied by using the surface sensitive technique of the confocal scanning laser microscopic (CSLM) technique including corrosion tests and electrochemical measurements. The higher corrosion rate of the W-30Ti alloy (i.e., about $3 \times 10^{-2} \mathrm{~mm} / \mathrm{y}$ ) than those of the $W$ 53Ti and W-90Ti alloys (i.e., about $4-5 \times 10^{-3} \mathrm{~mm} / \mathrm{y}$ ) was mostly due to the deep type of pitting corrosion observed on the surface of the passive film formed on the $\mathrm{W}$-30Ti alloy in $1 \mathrm{M} \mathrm{NaOH}$ solution. The shallow type of pits was developed on the surface of the passive film formed on the W-53Ti alloy, whereas no pitting corrosion on the titanium-rich W-90Ti alloy.
\end{abstract}

Keyword: pitting corrosion, open circuit corrosion potential, corrosion test, CSLM study.

\section{INTRODUCTION}

Corrosion science received extra impetus with the beginning of the $20^{\text {th }}$ century when steels were widely used (Uhlig \& Revie, 1991). Corrosion problems appeared with widespread uses of steels with high tensile strengths and of steel enforced concrete. Therefore, corrosion scientists and engineers strive to develop newer materials with enhanced corrosion resistance properties. Technologists generally ignore the corrosion scenario during the initial stages of design hoping to check it later by additional surface treatments. However, in most cases it is wiser to take into account the corrosion resistance properties at an earl stage of materials development. The applicability of any novel materials for industrial purposes and developmental areas is ultimately determined by their long-term corrosion resistance in its environment.

It is widely recognized that tungsten and titanium metals are effective alloying elements in order to enhance corrosion resistance of alloys in aggressive environments. Tungsten is corrosion-resistant particularly in non-oxidizing environments (Pourbaix, 1947). On the other hand, titanium is also widely recognized as one of the most effective alloying elements for preparing the corrosion-resistant amorphous or nanocrystalline alloys which provide a high passivating ability in oxidizing environments containing chloride ions (Pourbaix,

Mr. Bhattarai is Associate Professor in Science at Central Department of Chemistry, Tribhuvan University, Kirtipur, Kathmandu, Nepal.. 


\section{THE CONFOCAL SCANNING LASER...}

1974). Furthermore, regarding the potential-pH diagrams of tungsten and titanium, tungsten is hardly corroded by most of acid solutions except some complexing acids. On the other hand, tungsten metal corrodes in alkaline solutions while titanium metal does not corrode (Pourbaix, 1974).

Titanium-base alloys were originally developed in the early 1950s for aerospace applications because of their high strength-to-density ratios and these alloys showed excellent resistance to corrosive environments. It has been reported that the high corrosion resistance to titanium-base alloys has been attributed to the formation of a very stable, continuous, highly adherent and protective amorphous oxide films on the surface (Uhlig \& Revie, 1991). Titanium metal is highly reactive and has an extremely high affinity for oxygen and a beneficial surface amorphous oxide films are formed spontaneously when fresh titanium metal surface is exposed to air and/or aggressive environments (Asami et al., 1990; Habazaki et al., 1998). Sputter-deposited amorphous and/or nanocrystalline W-Ti alloys exhibited very high corrosion resistance in concentrated hydrochloric acids (Bhattarai, 1998, 2000; Bhattarai et al., 1995, 2000; Hashimoto et al., 1998) and alkaline solutions (Sharmah et al., 2007). They have studied the role of titanium in the passivation behaviour of the sputter-deposited $\mathrm{W}$ - Ti alloys in concentrated hydrochloric acid solutions at $30^{\circ} \mathrm{C}$ and reported that the amorphous or nanocrystalline $\mathrm{W}-\mathrm{Ti}$ alloys are passivated spontaneously so as to show significantly high corrosion resistance in HCI solutions. The W-Ti alloys containing 4-58 at\% titanium showed lower corrosion rates than those of the alloy constituting elements (that is, tungsten and titanium) in concentrated hydrochloric acids (Bhattarai, 1998; Bhattarai et al., 1995). Furthermore, the present author had reported that the corrosion-resistant of the $\mathrm{W}$-Ti alloys had increased with increasing titanium content and the corrosion rates of the alloys containing 53 at\% or more titanium are nearly two orders of magnitude lower corrosion rate than that of tungsten in alkaline $1 \mathrm{M} \mathrm{NaOH}$ solution as shown in Fig. 1 (Sharmah et al., 2007). One order of magnitude higher corrosion rate of the W-30Ti alloy than those of the alloys containing 53 at\% or more titanium was mainly due to pitting corrosion in $1 \mathrm{M} \mathrm{NaOH}$ solution. Therefore, it is very interesting to study the mechanism of the pitting corrosion on the W-Ti alloys surface using confocal scanning laser microscope (CSLM). 


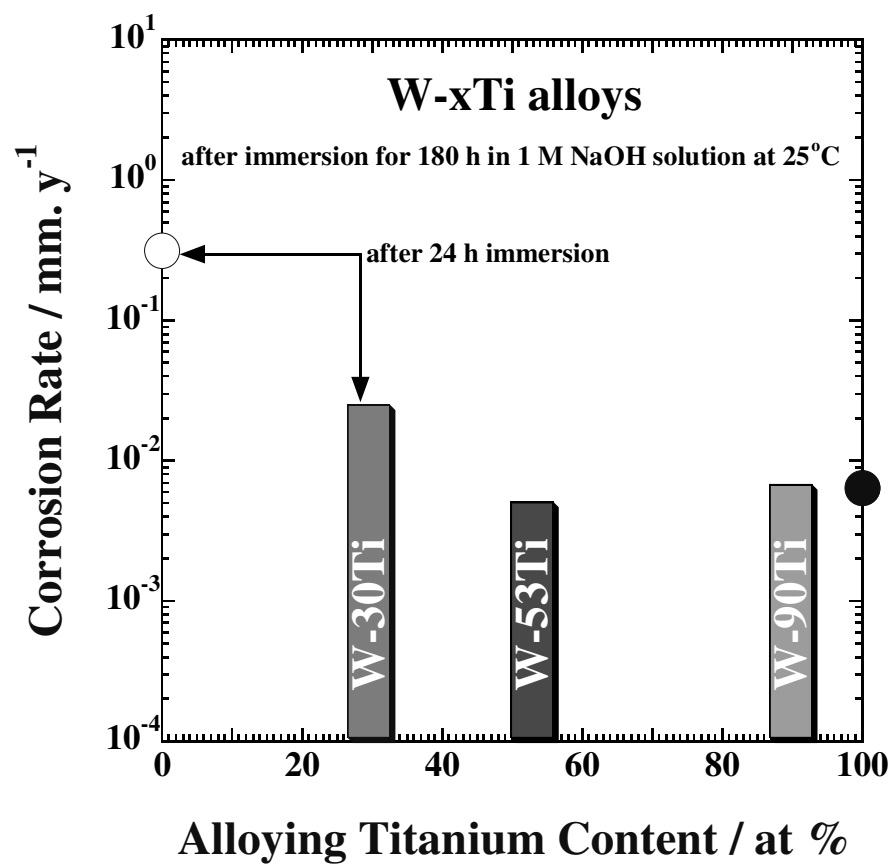

Figure 1: Changes in corrosion rates of the sputter-deposited W-Ti alloys in alkaline $1 \mathrm{M} \mathrm{NaOH}$ solution, as a function of titanium content (Sharmah et al., 2007).

In corrosion studies, the surface phenomenon plays a vital role. The surface reaction of interest include anodic dissolution, passivation and passivity breakdown (localized ruptures of the passive film) leading to localized corrosion like pitting corrosion (Uhlig \& Revie, 1991). Understanding these surface phenomena is very important to find remedies to corrosion problems, which are extremely costly.

In this context, the research work was aimed at studying the pitting corrosion in the surface of the passive films formed on the W-Ti alloys in alkaline $1 \mathrm{M} \mathrm{NaOH}$ solution at $25^{\circ} \mathrm{C}$ using corrosion tests, electrochemical measurements and CSLM techniques.

\section{METHODOLOGY}

Prior to the corrosion tests, electrochemical measurements and surface morphological studies, the sputter-deposited amorphous or nanocrystalline $\mathrm{W}-\mathrm{Ti}$ alloy specimens were mechanically polished with a silicon carbide paper up to grit number 1500 in cyclohexane, degreased by acetone and dried in air. The corrosion rate was estimated from the weight loss after immersion for $180 \mathrm{~h}$ in $1 \mathrm{M} \mathrm{NaOH}$ solution at $25^{\circ} \mathrm{C}$, open to air. The weight loss measurements for each alloy specimen was done two times or more and the average corrosion rate of individual alloy was estimated. The 


\section{THE CONFOCAL SCANNING LASER...}

open circuit potential was measured after immersion for 1 hour in $1 \mathrm{M} \mathrm{NaOH}$ solution at $25^{\circ} \mathrm{C}$, open to air. A platinum mesh and saturated calomel electrode were used as the counter and reference electrodes, respectively. The alloy specimen was used as a working electrode. All the potentials given in this paper are relative values to saturated calomel electrode (SCE).

The change in surface morphology and pitting corrosion of the sputterdeposited amorphous or nanocrystalline $\mathrm{W}-\mathrm{Ti}$ alloys before and after immersion for various times in $1 \mathrm{M} \mathrm{NaOH}$ solution at $25^{\circ} \mathrm{C}$ were studied using confocal scanning laser microscope (CSLM). As the laser source He-Ne having wavelength of $633 \mathrm{~nm}$ was used. The scan rates for the samples were varied from 1 to 6 per second.

\section{RESULTS AND DISCUSSION}

Figure 2 shows the changes in corrosion rates and open circuit potentials of the sputter-deposited amorphous or nanocrystalline W-Ti alloys including tungsten and titanium metals in alkaline $1 \mathrm{M} \mathrm{NaOH}$ solution at $25^{\circ} \mathrm{C}$, as the function of alloying titanium content. The corrosion rate of the W-Ti alloys decreased sharply with increasing titanium content and becomes almost constant at 53 at $\%$ or more titanium content. Furthermore, the corrosion rates of the amorphous or nancrystalline W-Ti alloys containing 53 at\% or more titanium are nearly two orders of magnitude lower than that of tungsten and cannot exceed than that of titanium metal in $1 \mathrm{M} \mathrm{NaOH}$ solution as $25^{\circ} \mathrm{C}$. In particular, the corrosion rate of the $\mathrm{W}-30 \mathrm{Ti}$ alloy shows nearly one order of magnitude higher corrosion rate than that of the W-53Ti alloy in $1 \mathrm{M} \mathrm{NaOH}$, eventhough the open circuit potentials of the W-30Ti and W-53Ti alloys are almost same value. The open circuit potentials of the W-Ti alloys containing 53 at\% or less titanium content are almost in the same range of 760 to $-730, \mathrm{mV}$ (SCE). However, the open circuit potential of the W-90Ti alloy is significantly shifted to more positive direction (that is, $-315 \mathrm{mV}$ vs SCE) and is located close to that of titanium metal, and hence the corrosion rate of the W-90Ti alloy is almost same as that of the titanium metal as shown in Fig. 2. In this context, this work is further focused to investigate the changes in the surface morphology of the passive films formed on the W-Ti alloys in alkaline solutions. 


\section{Alloying Titanium Content / at \%}

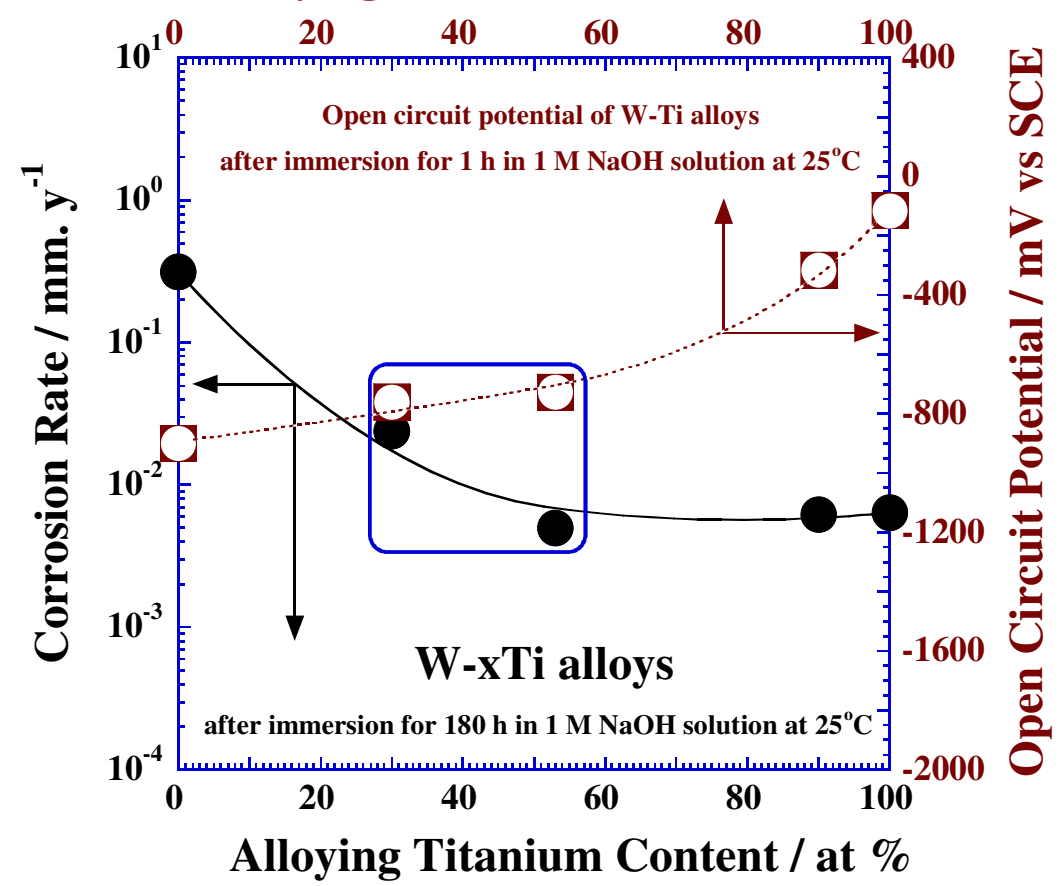

Figure 2: Changes in corrosion rate and open circuit potential of the sputterdeposited W-Ti alloys including tungsten and titanium metals in $1 \mathrm{M}$ $\mathrm{NaOH}$ solution at $25^{\circ} \mathrm{C}$, as a function of titanium content in the alloys.

In general, the change in the surface morphology of the alloys gives important information about the dissolution processes in nano-scales to study the passivation as well as corrosion behavior of the alloys. Figures 3(a) and $\mathbf{3}(\mathbf{b} \boldsymbol{\&}$ c) show CSLM images of the W-30Ti alloy before and after immersion for $12 \mathrm{~h}$ in $1 \mathrm{M} \mathrm{NaOH}$ solution at $25^{\circ} \mathrm{C}$, respectively. These images clearly revealed that the surface oxide-film formed on the as-prepared sputter-deposited W-30Ti alloy is very smooth and highly reflective as shown in Fig. 3(a) and the passive film formed on the W-30Ti alloy after immersion for $12 \mathrm{~h}$ in $1 \mathrm{M} \mathrm{NaOH}$ solution is different than those of the oxide-films of the alloys as shown in Figs 3(b) and (c). The dissolution is obvious and surface is roughened considerably in $1 \mathrm{M} \mathrm{NaOH}$ solution. In particular, the pitting corrosion is observed for the W-30Ti alloy after $12 \mathrm{~h}$ immersion in $1 \mathrm{M} \mathrm{NaOH}$ solution. 


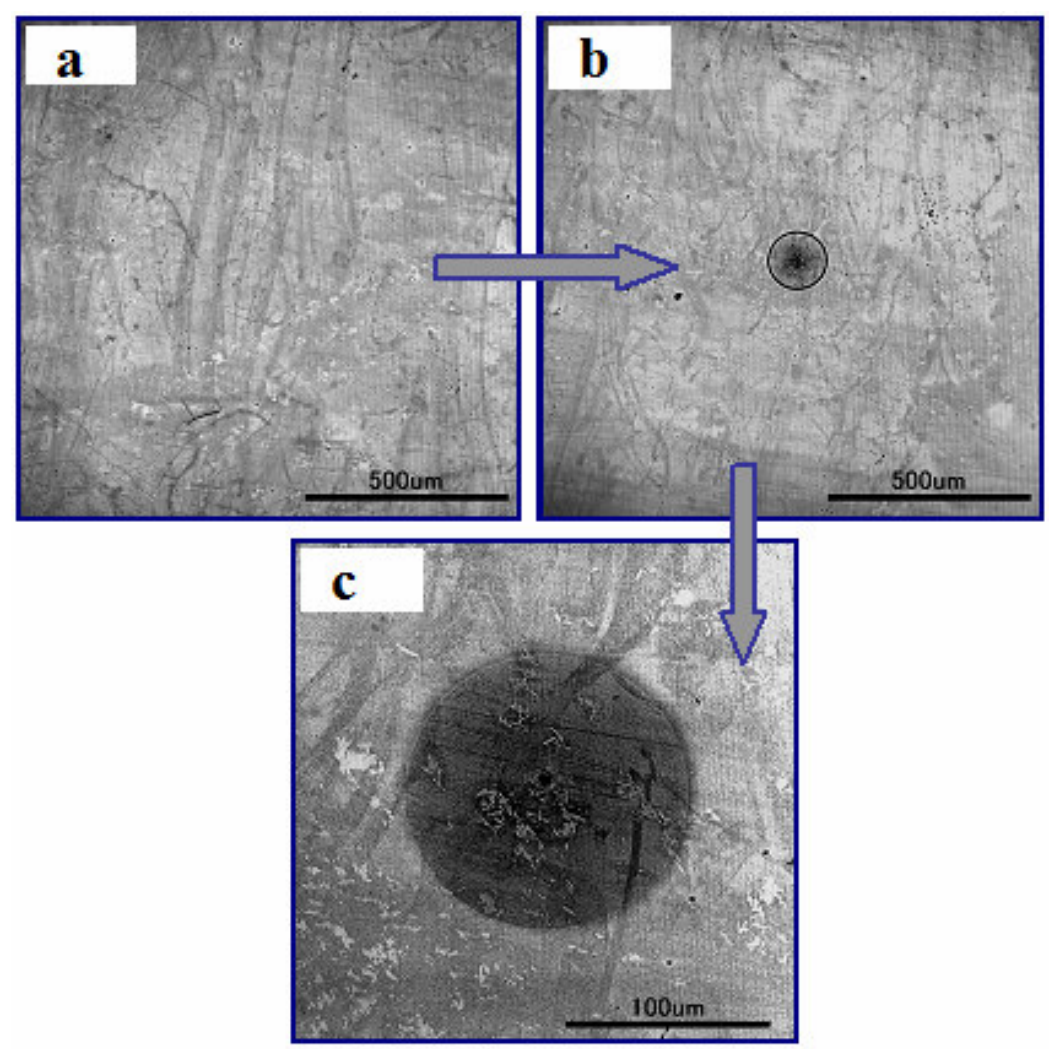

Figure 3: The confocal scanning laser microscopic images of the films formed on the W-30Ti alloy (a) before and (b \& c) after immersion for 12 hours in $1 \mathrm{M}$ $\mathrm{NaOH}$ solution at $20^{\circ} \mathrm{C}$, open to air

Furthermore, a detrimental type of pitting corrosion is clearly observed on the surface of the W-30 Ti alloy after immersion for 24 hours in alkaline $1 \mathrm{M}$ $\mathrm{NaOH}$ solution as shown in Fig. 4. Number of pits per area on the surface of passive film formed on the tungsten-rich W-30Ti alloy after immersion for $24 \mathrm{~h}$ (Fig. 4.a) is more than that on the surface of the alloy after immersion for $12 \mathrm{~h}$ (Fig. 3.b) in $1 \mathrm{M} \mathrm{NaOH}$ solution. On the other hand, it is clearly observed that the pitting factor on the surface of the W-30Ti alloy is increased with immersion time, although the deep pitting is formed on the passive films formed on the W-30Ti alloy in alkaline solutions. Therefore, the corrosion rate of the W-30Ti alloy should be increased with increasing the immersion times in $1 \mathrm{M} \mathrm{NaOH}$. 

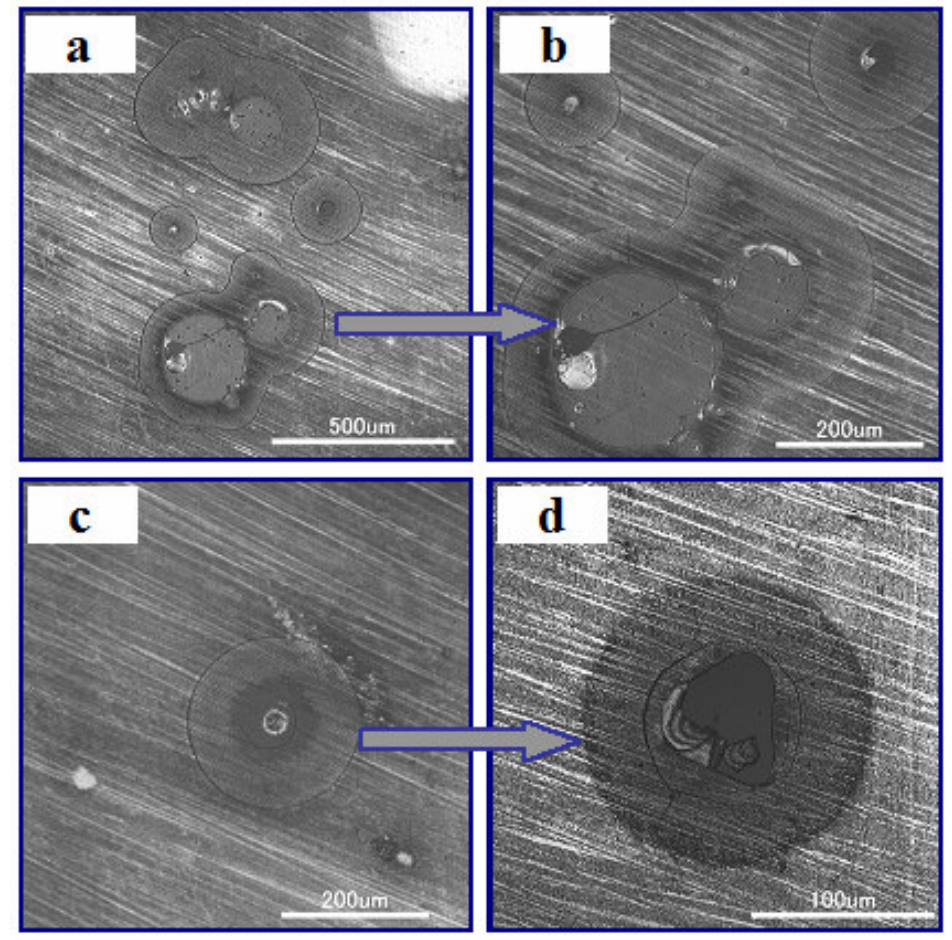

Figure 4: The confocal scanning laser microscopic images of the passive films formed on the W-30Ti alloy after immersion for 24 hours in $1 \mathrm{M}$ $\mathrm{NaOH}$ solution at $25^{\circ} \mathrm{C}$, open to air.

On the other hand, the nature of the pitting corrosion on the surface of the passive films formed on the W-53Ti alloy after immersion for $24 \mathrm{~h}$ in $1 \mathrm{M}$ $\mathrm{NaOH}$ solution is not so detrimental type as shown in Fig. 5. In the case of the W-53Ti alloy, the pits on the surface of the alloy are not of the deep type of pitting. It is shallow type of pitting corrosion and hence the W-50Ti alloy shows high corrosion resistance than that of the $\mathrm{W}$-30Ti alloy in $1 \mathrm{M} \mathrm{NaOH}$ solution as shown in Fig. 2. In particular, the localized breakdown of the passive film formed on the W-30Ti alloy is more clearly observed than that of the W-53Ti alloy. However, it is noteworthy to mention here that the pitting corrosion is not observed on the surface of the passive film formed on the titanium-rich W-90Ti alloy after immersion for 24 hours in alkaline $1 \mathrm{M} \mathrm{NaOH}$ solution at $25^{\circ} \mathrm{C}$ as shown in Fig. 6. These results clearly revealed that the high corrosion rate of the $\mathrm{W}-30 \mathrm{Ti}$ alloy than those of the W-53Ti and W-90Ti alloys is mostly due to the deep type of pitting corrosion ton the surface of the passive film formed on the W-30Ti alloy in $1 \mathrm{M} \mathrm{NaOH}$ solution. 
24 THE CONFOCAL SCANNING LASER...
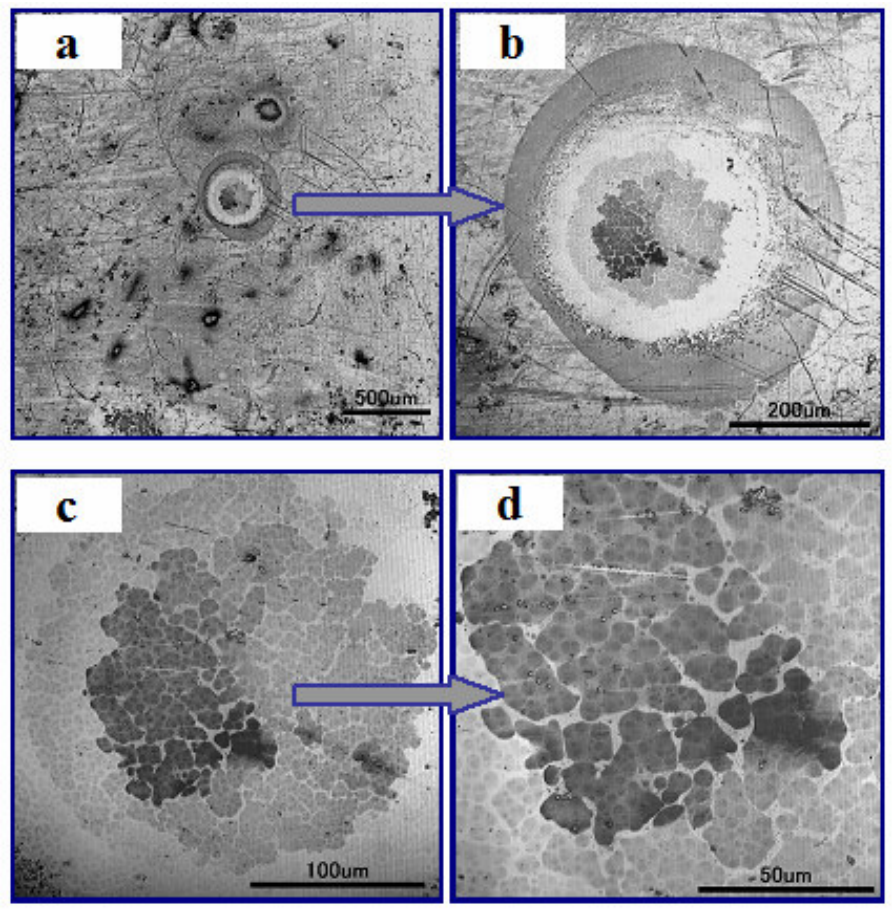

Figure 5: The confocal scanning laser microscopic image of the passive film formed on the W-53Ti alloy after immersion for 24 hours in $1 \mathrm{M}$ $\mathrm{NaOH}$ solution at $25^{\circ} \mathrm{C}$, open to air

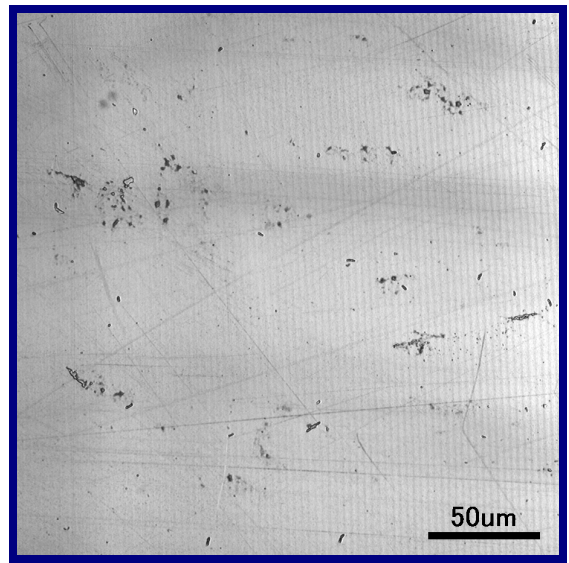

Figure 6: The confocal scanning laser microscopic image of the passive film formed on the W-90Ti alloy after immersion for 24 hours in $1 \mathrm{M}$ $\mathrm{NaOH}$ solution at $25^{\circ} \mathrm{C}$, open to air 


\section{CONCLUSIONS}

The mechanism of the pitting corrosion on the surface of the passive films formed on the sputter-deposited amorphous or nanocrystalline W-Ti alloys in $1 \mathrm{M} \mathrm{NaOH}$ solution at $25^{\circ} \mathrm{C}$, open to air is studied by corrosion tests, electrochemical measurements and confocal scanning laser microscopic (CSLM) techniques. The CSLM techniques are used to study the changes in the surface morphology and the mechanism of corrosion on the surface of the alloys. The following conclusion are drawn:

1. The corrosion rate of the amorphous W-30Ti alloy showed nearly one order of magnitude higher corrosion rate than that of the W-53Ti alloy.

2. The corrosion rate of the nanocrystalline W-90Ti alloy was almost the same as those of the W-53Ti alloy and titanium metal in $1 \mathrm{M} \mathrm{NaOH}$ solution at $25^{\circ} \mathrm{C}$.

3. High corrosion rate of the W-30Ti alloy than those of the W-53Ti and W-90Ti alloys could be mostly due to the deep type of pitting corrosion on the surface of the passive film formed on the W-30Ti alloy.

4. The deep type of pitting corrosion was clearly observed on the surface of the passive films formed on the tungsten-rich W-30Ti alloy only after immersion for $24 \mathrm{~h}$ in $1 \mathrm{M} \mathrm{NaOH}$ solution.

5. The open circuit corrosion potential of the titanium-rich W-90Ti alloy had significantly shifted to more positive direction than those of the W$30 \mathrm{Ti}$ and W-53Ti alloys after one hour immersion in $1 \mathrm{M} \mathrm{NaOH}$ solution, and is located very close to that of titanium metal.

\section{ACKNOWLEDGEMENTS}

The author is very thankful to the Head of Central Department of Chemistry, Tribhuvan University, Kirtipur, Kathmandu, Nepal for providing the available research facilities to conduct this research work. Sincere thanks to Dr. Himendra Jha, Post-doctoral Fellow at the LIMSA, Hokkaido University, Japan, for his kind helps for taking the CSLM images.

\section{WORKS CITED}

Asami, K., Chen, S.C., Habazaki, H., Kawashima, A. \& Hashimoto, K. 1990. Corros. Sci., 31, 727.

Bhattarai, J. 1998. Tailoring of Corrosion Resistance Tungsten Alloys by Sputtering. Ph.D. Thesis, Department of Materials Science, Japan: Tohoku University, pp. 229.

Bhattarai, J. 2000, J. Nepal Chem. Soc., 19, 1.

Bhattarai, J., Akiyama, E., Kawashima, A., Asami, K. \& Hashimto, K. 1995. Corros. Sci., 37, 2071. 
Bhattarai, J., Kawashima, A., Asami, K. \& Hashimoto, K. 2000. in Proc. $3^{\text {rd }}$ National Conference on Science and Technology, RONAST. Kathmandu, Nepal, Vol. 1, 389.

Habazaki, H., Takahiro, K., Yamaguchi, S., Shimizu, K., Skeldon, P., Thompson, E.G. \& Wood, C.G. 1998. Philos. Mag. A, 78[1], 171-187.

Hashimoto, K., Bhattarai, J., Li, X.Y., Park, P.Y., Kim, J.H., Akiyama, E., Habazaki, H., Kawashima, A., Asami, K. \& Shimamura, K. 1998. in Proc. of the Special Symposium on Passivity and its Breakdown (eds. P.M. Natishan, H. S. Issacs, M. Janik-Czachor, V. A, Macagno, P. Marcus and M. Seo). pp. 369-383. The Electrochemical Society Inc., 10 South Main St., Pennington, NJ, USA.

Pourbaix, M. 1974. in Atlas of Electrochemical Equilibrium in Aqueous Solution. pp. 213-280, National Association of Corrosion Engineers Huston, TX.

Sharmah, A., Jha, H. \& Bhattarai, J. 2007. J. Nepal Chem. Soc., 22, 17, Uhlig, H.H. and Revie, R.W. 1991 in Corrosion and Corrosion Control, $3^{\text {rd }}$ edition, pp.441. 